\title{
Previdência Complementar dos Servidores Estatutários: estudo de caso dos servidores de uma Instituição Pública
}

Supplementary Pension of Statutory Employees: case study of the employees of a Public Institution

Pensión Complementaria de los Empleados Legales: estudio de caso de los empleados de una Institución Pública

Recebido: 30/08/2021 | Revisado: 04/09/2021 | Aceito: 07/09/2021 | Publicado: 09/09/2021

\author{
Rodrigo Aires de Oliveira \\ ORCID: https://orcid.org/0000-0003-0915-5706 \\ Universidade Federal Rural do Rio de Janeiro, Brasil \\ E-mail: airesrodrigo.oliveira@gmail.com \\ Maria Cristina Drumond e Castro \\ ORCID: https://orcid.org/0000-0001-7562-7367 \\ Universidade Federal Rural do Rio de Janeiro, Brasil \\ E-mail: cristina.ufrrj.itr@gmail.com
}

\begin{abstract}
Resumo:
A partir do surgimento do Regime de Previdência Complementar, todos os servidores públicos federais que ingressaram antes da criação da Fundação de Previdência Complementar do Servidor Público Federal do Poder Executivo - Funpresp, com direito à integralidade, podem migrar, por prévia e expressa opção, em caráter irrevogável e irretratável, para o RPC. Nesse cenário, nota-se um dilema, entre os servidores públicos civis estatutários, em relação à possibilidade de migrar para o RPC. A análise do perfil dos servidores e a motivação que os levaram a não optar pela migração para o RPC podem colaborar com o entendimento dos órgãos de gestão de pessoas do serviço público no que diz respeito à elaboração de treinamentos mais específicos e voltados a questões identificadas no presente estudo. Diante de tal situação, o presente estudo tem como objetivo identificar quais são as justificativas dadas pelos servidores públicos federais que não migraram para o RPC e, consequentemente, não aderiram à Funpresp. Como metodologia, foi aplicado um questionário com os servidores que estavam exercendo suas atividades em uma Instituição Pública, e que ainda não tinham optado pela migração de regime. A partir dos dados obtidos, constatou-se que as principais justificativas para a não adesão à Previdência Complementar são a idade, o tempo de contribuição restante para a aposentadoria, a incerteza quanto ao valor futuro do benefício especial, a incerteza quanto à segurança jurídica no pagamento futuro do benefício especial e o risco de má gestão nos investimentos do plano.
\end{abstract}

Palavras-chave: Migração previdenciária; Funpresp; Regime de previdência complementar.

\begin{abstract}
From the emergence of the Supplementary Pension Scheme, all federal public servants who joined before the creation of the Complementary Pension Foundation of the Federal Public Servant of the Executive Branch - Funpresp, entitled to full, can migrate, by prior and express option, irrevocable and irrevocably, to the PRC. In this scenario, there is a dilemma among statutory civil servants regarding the possibility of migrating to the PRC. The analysis of the profile of the servants and the motivation that led them not to opt for migration to the PRC can contribute to the understanding of the people management bodies of the public service with regard to the preparation of more specific training and focused on issues identified in the present study. In view of this situation, the present study aims to identify what are the justifications given by federal public servants who did not migrate to the PRC and, consequently, did not join Funpresp. As a methodology, a questionnaire was applied with the servers who were performing their activities in a Public Institution, and who had not yet opted for regime migration. From the data obtained, it was found that the main reasons for non-access to the Supplementary Pension are age, the remaining contribution time to retirement, the uncertainty as to the future value of the special benefit, the uncertainty regarding legal certainty in the future payment of the special benefit and the risk of mismanagement in the investments of the plan.
\end{abstract}

Keywords: Social security migration; Funpresp; Supplementary pension scheme.

\section{Resumen}

A partir de la aparición del Régimen complementario de pensiones, todos los servidores públicos federales que se adjunten antes de la creación de la Fundación De Pensiones Complementarias del Servidor Público Federal del Poder Ejecutivo - Funpresp, con derecho a la totalidad, pueden migrar, por opción previa y expresa, irrevocable e irrevocable, a la República Popular China. En este escenario, existe un dilema entre los funcionarios públicos estatutarios con respecto a la posibilidad de migrar a la República Popular China. El análisis del perfil de los 
servidores y la motivación que los llevó a no optar por la migración a la RPC puede contribuir a la comprensión de los órganos de gestión de personas de la administración pública con respecto a la preparación de una formación más específica y centrada en los temas identificados en el presente estudio. Ante esta situación, el presente estudio tiene como objetivo identificar cuáles son las justificaciones dadas por los servidores públicos federales que no migraron a la República Popular China y, en consecuencia, no se afiliaron a la Funpresp. Como metodología, se aplicó un cuestionario con los servidores que estaban realizando sus actividades en una Institución Pública, y que aún no habían optado por el régimen de migración. A partir de los datos obtenidos, se constató que los principales motivos de no acceso a la Pensión Complementaria son la edad, el tiempo de cotización restante a la jubilación, la incertidumbre en cuanto al valor futuro de la prestación especial, la incertidumbre respecto a la seguridad jurídica en el futuro pago de la prestación especial y el riesgo de mala gestión en las inversiones del plan.

Palabras clave: Migración a la seguridad social; Funpresp; Régimen complementario de pensiones.

\section{Introdução}

As Entidades Fechadas de Previdência Complementar - EFPC, também conhecidas como fundos de pensão, integram o sistema de previdência social brasileiro e constituem importante instrumento de proteção adicional ao trabalhador e mecanismo de formação de poupança interna a longo prazo, necessárias para ampliar a capacidade de investimento do país e diversificar as fontes de financiamento do crescimento econômico.

Segundo dados da Superintendência Nacional de Previdência Complementar - Previc, órgão responsável por supervisionar e fiscalizar as EFPC, em dezembro de 2020, existiam 292 EFPC no Brasil (181 de patrocínio privado, 89 de patrocínio público e 22 de instituidores), 1.129 planos de benefícios, com ativos totais na ordem de $\mathrm{R} \$ 1,05$ trilhões (Superintendência Nacional de Previdência Complementar [PREVIC], 2021), ocupando a 9a posição do ranking global dos fundos de pensão (Organização para Cooperação e Desenvolvimento Econômico [OCDE], 2021).

A população de participantes protegida pelas EFPC supera 7,2 milhões de pessoas, compreendendo 3,6 milhões de participantes e assistidos (aposentados e pensionistas), 3,6 milhões de pessoas designadas (pessoas indicadas pelo participante ou assistido, passíveis de terem direito a benefícios, de acordo com as regras estabelecidas no regulamento do plano) e 3.330 patrocinadores e instituidores (PREVIC, 2020). Diante desses dados, destaca-se que a Previdência Complementar exerce um papel de suma importância na política atual de gestão de pessoas no Serviço Público Federal.

O Regime de Previdência Complementar (RPC), como o próprio nome já indica, complementa o sistema de previdência público, visando suprir a necessidade de renda adicional na aposentadoria. As EFPC administram planos previdenciários patrocinados por empresas ou instituídas por entidades associativas, podendo ser oferecidos a participantes que possuam vínculo empregatício, servidores públicos dos Entes Federativos e associados ou membros de entidades de classe e associações.

Nesse contexto, a Lei no 12.618, de 30 de abril de 2012, instituiu o Regime de Previdência Complementar para os servidores públicos federais e autorizou a criação da Fundação de Previdência Complementar do Servidor Público Federal (Funpresp). A partir da referida norma, todos os servidores do executivo que ingressaram nos quadros do Poder Executivo federal, antes de 04 de fevereiro de 2013, tiveram a opção de aderir ao RPC, como forma de complementar sua aposentadoria, por ocasião da inatividade, e manter um padrão de vida similar ao que possuía durante a fase ativa (Angoti, 2012).

A Funpresp-Exe entrou em funcionamento com a publicação da Portaria Ditec/Previc/MPS no 604, em 02 de outubro de 2012, que aprovou o seu Estatuto e, em 04 de fevereiro de 2013, com a publicação da Portaria Ditec/Previc/MPS no 44, foi sancionado o Regulamento do Plano de Benefícios do Executivo Federal, passando a oferecê-lo aos novos servidores públicos do Poder Executivo admitidos a partir da referida data.

Não se pode olvidar que as reformas na Previdência Social delinearam limitações para a obtenção de benefícios, com tetos cada vez menores. Por essa razão, a Previdência Complementar passou a ser considerada uma necessidade para os servidores e suas respectivas famílias (Cazassa, 2002). 
Segundo dados do Ministério da Economia, mediante a política de ajuste das contas públicas do Governo Federal, pretendia-se economizar mais de R \$ 60 milhões no triênio 2018/2020 com a mudança no regime previdenciário dos servidores (Batista, 2021). Desse modo, o governo passaria a ser responsável pelo pagamento dos benefícios até o teto estabelecido para o Regime Geral de Previdência Social - RGPS. Por outro lado, a União tem um aumento nos seus gastos com os aportes nas Fundações de Previdência Complementar dos servidores, o qual é compensado com a redução da Contribuição do Plano de Seguridade Social do Servidor.

O RPC está capitulado nos $\S \S 14$ ao 16 do artigo 40, bem como no artigo 202 da Constituição Federal, sendo de caráter facultativo e autônomo em relação ao Regime Geral de Previdência Social (Brasil, 1988). A legislação prevê que o mesmo será administrado pelas EFPC, nos entes federativos quais sejam, a União, os Estados, o Distrito Federal e os Municípios.

A Previdência Complementar no Brasil surgiu, de forma regulamentar, com a Lei no 6.435, de 1977, em consonância com a experiência norte-americana do ERISA (Employee Retirement Income Security Act), na necessidade de regulamentação dos montepios, da canalização da poupança previdenciária ao desenvolvimento do mercado de capitais no País a partir do $2^{\circ}$ Programa Nacional de Desenvolvimento e do funcionamento de entidades de previdência privada ligadas ao setor estatal (Pinheiro, 2008, p. 13).

O movimento de modernização da legislação que rege a Previdência Complementar teve início com a Emenda Constitucional no 20, de 15 de dezembro de 1998 (Brasil, 1998), dando nova redação ao art. 202 da Constituição Federal, o qual se dedicou inteiramente à Previdência Complementar, sob a finalidade de regulamentar a PC dentro do título da Ordem Social da Constituição Federal (Paixão, 2007).

A legislação vigente prevê três tipos de previdência: o Regime Geral de Previdência Social (destinado aos trabalhadores da iniciativa privada e aos empregados públicos), o Regime Próprio (para servidores públicos titulares de cargo efetivo da União, dos Estados, do Distrito Federal e dos Municípios) e o Regime de Previdência Complementar (facultativo e de caráter privado) (Associação Nacional dos Advogados Públicos Federais [ANAFE], 2018).

O RPC é formado pelas EFPC, também conhecidas como Fundos de Pensão, e pelas Entidades Abertas de Previdência Complementar - EAPC. As EFPC são denominadas fechadas, uma vez que são acessíveis exclusivamente aos empregados de uma empresa ou grupo de empresas e aos servidores da União, dos Estados, do Distrito Federal e dos Municípios, denominados patrocinadores; e aos associados ou membros de pessoas jurídicas de caráter profissional, classista ou setorial (instituidores), conforme disposto na Lei Complementar no 109/01 (Brasil, 2001). Já as Entidades Abertas são sociedades anônimas que possuem fins lucrativos.

Pulino (2011, p. 125) descreve cinco diferenças entre entidades abertas e fechadas: (i) a forma de organização da entidade; (ii) a representação dos participantes nos órgãos estatutários das entidades; (iii) a finalidade lucrativa; (iv) o acesso à entidade sob o ponto de vista tanto da pessoa física aderente quanto da pessoa jurídica contratante (empresa, ou associação de caráter setorial, classista ou profissional); e (v) os órgãos de regulação e fiscalização a que se submetem cada modalidade dessas entidades.

Com a criação do Regime de Previdência Complementar, todos os servidores públicos federais que ingressaram antes da criação da Funpresp, com direito à integralidade ou quase integralidade do benefício previdenciário, puderam migrar, por prévia e expressa opção, em caráter irrevogável e irretratável, para o RPC. Aqueles que não optaram pela migração de regime, durante os prazos de abertura $^{1}$, continuaram vinculados ao Regime Próprio de Previdência, somente podendo aderir ao RPC

${ }^{1}$ Lei no 12.618, de 30 de abril de 2012 (Prazo de migração: de 04/02/2013 a 04/02/2015); Lei no 13.328, de 29 de julho de 2016 (Prazo de migração: de 29/07/2016 a 29/07/2018) e Lei no 13.809, de 21 de fevereiro de 2019 (Prazo de migração: de 25/09/2018 a 29/03/2019). 
mediante nova abertura do processo de migração, o qual já vem sendo discutido por diversos órgãos de classe e integrantes do Governo Federal.

Nesse cenário, observam-se que 188.535 servidores civis, ativos ${ }^{2}$, do Poder Executivo Federal de todo o Brasil, que ingressaram no Poder Executivo Federal antes de 04 de fevereiro de 2013, ainda não realizaram a migração, talvez por não disporem das informações necessárias, ou por desconhecerem qual seria a opção mais vantajosa para o recebimento da sua aposentadoria, devido à grande quantidade de variáveis envolvidas na tomada de decisão, à complexidade das regras de cálculo do valor do benefício, ao cenário macroeconômico, aos riscos dos investimentos, ao risco político, às reformas no sistema previdenciário, dentre outros.

Por outro lado, verificou-se que 15.339 servidores públicos civis do país migraram para o RPC, sendo que, deste total, 82,92\% resolveram aderir à Funpresp. O presente estudo visa analisar o perfil dos servidores e as principais motivações que os levaram a não aderir à migração para o RPC, com a consequente adesão à Fundação de Previdência Complementar do Servidor Público Federal, sendo dividido da seguinte forma: introdução, seguida do referencial teórico. A terceira seção é dedicada a apresentar a metodologia utilizada. Na quarta seção é apresentada a análise dos resultados. Por fim, são apresentadas considerações finais e sugestões para estudos futuros.

\section{Fundamentação}

O sistema previdenciário é composto por três regimes distintos: Regime Geral de Previdência Social (RGPS), destinado aos contribuintes do setor privado ou da economia familiar no meio rural; Regime Próprio de Previdência Social (RPPS), proposto para servidores públicos efetivos da União, Estados, Distrito Federal e Municípios; e Previdência Complementar, que possui filiação facultativa e funciona como um seguro individual.

O RGPS é o mais importante dos três subsistemas, por ter emitido a maior quantidade de benefícios, estando, assim, no destaque do sistema brasileiro de proteção social (Giambiagi, 2007; Rangel, 2013).

De acordo com os dados apresentados, atesta-se que o modelo previdenciário brasileiro está dividido em três tipos de sistemas de previdência:

Sistema de capitalização - cria-se uma poupança individual e não existe solidariedade, sendo representado pelos RPCF e RPCA; b) Sistema de repartição simples - há solidariedade para a contribuição em um fundo que é usado em casos de eventos que demandem cobertura; nesse caso, as receitas atuais pagarão as despesas atuais e, portanto, não há formação de poupança individual, representado pelo RGPS e RPPS; e c) Combinação dos dois sistemas - hipótese destinada aos trabalhadores celetistas que pretendem cumular benefícios do RGPS e de uma EFPC ou EAPC e os servidores públicos, amparados pelo RPPS ou RGPS, de acordo com o vínculo estatutário ou celetista; pode-se, assim, acumular benefício do regime obrigatório (RPPS ou RGPS) com um das EAPC (Amaral, Giambiagi, \& Caetano, 2013).

Do mesmo modo, Giambiagi (2007) explica que o sistema de repartição atua como um contrato social entre as gerações sucessivas da população, uma vez que é a população ativa que financia o benefício da população inativa. Nesse sentido, para que haja um superavit previdenciário, a população ativa deve ser maior que a inativa.

No sistema de capitalização, segundo o autor, os trabalhadores devem contribuir para a formação de uma poupança individual, que futuramente se tornará o benefício a se receber (Giambiagi, 2007). Chaba (2013) completa que tais recursos são investidos em ativos existentes no mercado financeiro, possibilitando o seu crescimento (capitalização).

\footnotetext{
${ }^{2}$ Informação disponibilizada na Plataforma Integrada de Ouvidoria e Acesso à Informação do Ministério da Economia, em reposta à consulta realizada pelo pesquisador no site https://esic.cgu.gov.br/falabr.html. Acesso em 26/08/2020.
} 
Quanto ao sistema misto, que constitui a combinação do sistema de repartição e de capitalização, garante-se um salário pelo sistema de repartição simples, até um valor-limite (teto), demandando, assim, um plano de previdência privada pelo sistema de capitalização, o que, por sua vez, permite a complementação da aposentadoria (Chaba, 2013).

Vale pontuar que, com a instituição da Fundação de Previdência Complementar do Servidor Público Federal, os servidores estatutários passaram a ter o direito de acumular o benefício do regime obrigatório com um benefício da EFPC do servidor público, e não mais apenas com uma das EAPC.

Quanto aos planos de benefício dos sistemas previdenciários, conforme Ricaldoni (2012), podem ser de três tipos: plano de Benefício Definido (BD); plano de Contribuição Definida (CD); e plano de Contribuição Variável (CV). No BD, define-se o valor do benefício no momento da adesão, realizando a fórmula de cálculo ou do seu valor. O custeio desse plano é determinado anualmente, de modo a garantir sua concessão e manutenção. Já o plano de Contribuição Definida (CD) caracteriza-se pela formação de reservas individuais, não contemplando o mutualismo nas fases de contribuição e de concessão. É o modelo empregado pela Funpresp, cujo valor do benefício é calculado conforme reserva acumulada durante a fase de capitalização, decorrente de contribuições (pessoais e de patrocinador) vertidas a seu favor e do retorno líquido dos investimentos (Ricaldoni, 2012).

Diferente do Plano CD, no plano de Contribuição Variável (CV), o participante determina o valor de sua contribuição mensal, e o valor do benefício será o resultado desse aporte estimado. Nesse caso, o beneficiário terá direito a benefícios programados e os valores desses benefícios serão calculados de acordo com a idade, o gênero, os recursos acumulados e a taxa de juros vigente no momento da abertura do pedido de aposentadoria (Amaral et al., 2013). Dependendo do plano escolhido, o cálculo pode ser vitalício, a partir do cálculo atuarial realizado até o falecimento do participante ou por tempo determinado.

O RPC visa fornecer ao trabalhador uma proteção previdenciária adicional àquela oferecida pelo RGPS ou pelo RPPS, para os quais as contribuições dos trabalhadores são obrigatórias (Rangel, 2013). Como já mencionado, suas regras específicas são baseadas nas Leis Complementares no 108 e no 109, de 29 de maio de 2001.

Ricaldoni (2012) também explica que o RGPS e o RPPS são públicos e obrigatórios, e por esta última característica não se pode escolher entre contribuir ou não. Nos dizeres do autor, o modelo complementar possui caráter privado e facultativo, e abrange uma manifestação de vontade por meio contratual (contrato privado de adesão).

De acordo com Kertzman e Martinez (2018), o RPPS é destinado aos servidores públicos efetivos estatutários, ou seja, aos trabalhadores nomeados pela administração pública direta, autárquica ou fundacional, lotados em cargos públicos, que possuam normas previdenciárias previstas no estatuto de trabalho. Dessa forma, cada Estado elabora o seu próprio regime, especificando contribuições e benefícios, conforme legislação concernente. Vale salientar que a maioria dos municípios brasileiros ainda não possui regime próprio de previdência, e, por isso, os servidores acabam integrando-se ao RGPS.

Nesse sentido, vale salientar que a Previdência Complementar é o principal mecanismo capaz de proporcionar ao seu beneficiário a manutenção da sua qualidade de vida sem afetar seu poder de compra. A partir dessa adesão, o participante, quando aposentado, não irá depender exclusivamente da previdência social, evitando a diminuição da sua renda mensal (Filho, 2015).

A Lei no 12.618, de 30 de abril de 2012, instituiu o regime de Previdência Complementar para os servidores públicos federais titulares de cargos efetivos, determinando um teto para o pagamento de aposentadorias e pensões, e autorizando a criação de uma Entidade Fechada de Previdência Complementar (EFPC) denominada Fundação de Previdência Complementar do Servidor Público Federal (Funpresp).

Até então, os servidores só tinham à disposição as entidades de previdência complementar abertas, contudo, para compensar, suas aposentadorias não estavam condicionadas a um valor teto. A partir de 2012, os servidores puderam aderir a 
uma entidade de previdência complementar fechada, caso desejassem complementar o valor do benefício previdenciário do RGPS ou RPPS.

O servidor público que realizar a migração poderá receber um benefício especial, sendo o seu valor adicionado à sua aposentadoria, que será pago pelo RPPS da União, de acordo com as contribuições efetuadas e com o tempo de contribuição.

Amaral (2017) complementa que qualquer servidor pode contribuir para a Funpresp, mesmo que perceba remuneração menor que o teto do RGPS. Assim, caso deseje o complemento à sua aposentadoria, no caso daqueles que recebem acima do teto, conforme art. 16, § 3o , da Lei no 12.618/2012: o Governo contribuirá com 7,5 a 8,5\%, sempre na mesma proporção que servidor vier a contribuir.

Rangel (2013) acrescenta que o valor de contribuição mensal, conforme alíquota de 8,5\%, constitui um percentual menor de recolhimento em comparação aos $11 \%$ recolhidos atualmente pelos servidores vinculados apenas ao RPPS. Se a parte interessada julgar que os $8,5 \%$ não é suficiente para formar uma reserva em montante que garanta o consumo futuro, $o$ segurado pode investir os $2,5 \%$ "extras", que configura a diferença de alíquota de recolhimento em favor da previdência aplicável.

O regulamento do Plano Funpresp-Exe prevê os seguintes tipos de participantes: Ativo Normal (o servidor está vinculado ao teto do Regime Geral de Previdência Social e sua Base de Contribuição supera o teto estabelecido pelo RGPS) ou Ativo Alternativo (o servidor não se submete ao teto do Regime Geral de Previdência Social ou possui base igual ou inferior ao teto do RGPS), conforme informações da Funpresp (2020).

A Funpresp integra uma mudança de paradigma, uma vez que os riscos do sistema são transferidos integralmente para o servidor, afastando o Estado de sua função de garantidor social. Diante do binômio proteção social dos servidores públicos versus equilíbrio financeiro atuarial, de forma a compatibilizar a previdência social do servidor público com a nova realidade econômica e social do país, destaca-se essa alternativa de melhoria das contas do sistema, relacionada ao sistema de arrecadação e à melhor disciplina do modelo de concessão de benefícios, de acordo com os parâmetros de envelhecimento da população e com a redução do quadro de servidores ativos. Nesse contexto, acredita-se que a Funpresp seja suficientemente capaz de preservar os interesses dos aplicadores nos ditos fundos de previdência.

Os servidores que resolverem aderir à previdência complementar terão direito a um benefício composto por três parcelas, sendo a primeira análoga à contribuição ao RGPS, limitada ao teto, com a devida correção anual pelo Índice Nacional de Preços ao Consumidor (INPC); a segunda engloba um benefício especial que corresponde ao tempo de contribuição de acordo com a totalidade da remuneração, com correção pelo Índice Nacional de Preços ao Consumidor Amplo (IPCA) e multiplicado por um Fator de Conversão (FC); a terceira parcela diz respeito ao RPC, sendo paga pelo Fundo de Pensão e atualizada conforme rentabilidade do mercado (Chaba, 2013).

Nesse cenário, Pena (2014) salienta a importância atual da tecnologia, pois a segurança e o bom funcionamento dos fundos de pensão dependem desse recurso. Deve-se, assim, manter o constante aperfeiçoamento do aparato administrativo, tecnológico e de gestão de pessoas, com a finalidade de assistir seus participantes e patrocinadores. No âmbito de investimentos, a administração dos recursos financeiros da poupança previdenciária de longo prazo deve ponderar as melhores práticas de aquisições no que se refere à rentabilidade e gestão de riscos.

Na próxima seção, apresentam-se a metodologia de pesquisa, o percurso metodológico, as etapas do desenvolvimento da pesquisa de campo, incluindo o formulário a ser aplicado visando a simulação de um caso. Convém mencionar que essa simulação tem sido realizada pelo pesquisador, sendo apresentada como elemento de tomada de decisão para o caso estudado.

\section{Metodologia}

Como percurso metodológico, o presente estudo possui natureza de pesquisa aplicada e caráter descritivo-exploratório 
(Cervo \& Bervian, 2002). O presente estudo é caracterizado como exploratório, conforme explicam Selltiz, Wrightsman e Cook (1965), tendo-se como objetivo descrever ideias e intuições, na tentativa de adquirir maior familiaridade com o fenômeno pesquisado. Quanto ao caráter descritivo, segundo Selltiz et al. (1965), busca-se descrever um fenômeno ou situação em detalhe, permitindo detalhar, com exatidão, as características de um indivíduo, de uma situação, ou de um grupo, além de verificar a relação entre os eventos.

Quanto à consulta das literaturas científica e técnica, para levantamento do estado da arte e da literatura 'cinzenta', contemplou-se a produção intelectual de caráter científico que evidenciava contribuições intelectuais de caráter técnico/tecnológico, a exemplo da IPTEC - Revista Inovação, Projetos e Tecnologias, que "privilegia a contribuição de natureza técnica de um trabalho feito com propósitos profissionais, porém com o rigor da pesquisa científica" (Biancolino, Kniess, Maccari, \& Rabechini, 2012, p. 294).

A IPTEC - Revista Inovação, Projetos e Tecnologias é responsável por disseminar a produção intelectual aplicada à prática profissional nas áreas de inovação, gerenciamento de projetos, desenvolvimento de tecnologias e sustentabilidade, sendo voltada aos programas de pós-graduação stricto sensu de caráter profissional. Nesse sentido, realizaram-se a apresentação do tema, a fundamentação teórica com apresentação da literatura, a escolha metodológica fundamentada no objetivo proposto e a coleta e a análise dos dados e dos resultados, com o devido detalhamento de cada procedimento (Martens \& Pedron, 2019).

Em relação à abordagem, o trabalho se enquadra como pesquisa qualitativa, por ser necessário interpretar e analisar os diversos normativos que regem o regime de previdência social e complementar (Yin, 2016). Como procedimento de pesquisa, realiza-se um estudo de caso (Vergara, 2003; Yin, 2016; Pereira et al., 2018; Lüdke \& André, 2013), selecionando servidores para preencher um formulário-base para a análise do perfil e dos motivos que os levaram a não migrar para o RPC.

Para a execução da pesquisa, realizou-se uma amostra não probabilística, intencional, pois os elementos selecionados seguem um critério de julgamento pessoal do pesquisado. De acordo com Creswell (2014, p. 129), "o investigador seleciona indivíduos e locais para estudo porque eles podem intencionalmente informar uma compreensão do problema".

Para evidenciar os fatores que impactaram a decisão de não migrar para o regime de previdência complementar, utiliza-se a técnica de amostragem não-probabilística, a qual segundo Gil (2008) depende dos critérios do pesquisador, não utilizando de fundamentação estatística. O critério adotado foi o de acessibilidade, que, ainda de acordo com o autor citado, se caracteriza pelo fato de o pesquisador selecionar os elementos aos quais tem maior acesso, dispensando qualquer rigor estatístico.

Os participantes do estudo pertenciam a uma Instituição Pública, onde estes se enquadravam no requisito de ingresso no Serviço Público Federal com data de ingresso anterior à 04 de fevereiro de 2013 e sem a realização da opção pela migração para o RPC.

A primeira etapa da pesquisa foi a obtenção da autorização de pesquisa junto à Instituição Pública selecionada, cujo documento foi assinado em 10 de maio de 2021. Após a autorização, foi iniciada a seleção dos servidores que ainda não haviam migrado para o Regime de Previdência Complementar, sendo utilizados os dados abertos do Portal da Transparência do Governo Federal ${ }^{3}$, no qual foram selecionados os servidores de uma Instituição Pública (nome preservado), por meio da análise da ficha contendo sua remuneração.

Nessa ficha, observou-se o valor de desconto para o Plano de Seguridade Social do Servidor - PSS, onde foram escolhidos todos aqueles que possuíam valor de contribuição acima do teto do RGPS, que indicava a não opção pela migração para o RPC, pois servidores optantes por este Regime contribuem com valores limitados ao referido teto.

\footnotetext{
${ }^{3}$ http://www.portaltransparencia.gov.br/servidores/lista-consultas
} 
A Instituição possuía 391 servidores em exercício, sendo que apenas 60 se enquadravam nos critérios para a participação na pesquisa, dos quais 47 são do sexo masculino e 13 do sexo feminino. Com a lista de servidores aptos a participarem da pesquisa, o pesquisador encaminhou e-mail ao órgão de recursos humanos da Instituição Pública, para que esta conduzisse o questionário da pesquisa aos servidores que ainda não haviam optado pela migração para o RPC, juntamente ao Termo de Consentimento Livre e Esclarecido - TCLE.

Transcorrido o prazo estipulado de 20 dias para os servidores acessarem o link da pesquisa ${ }^{4}$, apenas 11 servidores deram o devido retorno, o que representa uma amostragem de aproximadamente $20 \%$ da população.

\section{Resultados e Discussão}

Como já mencionado na Metodologia, para a coleta de dados, foi solicitado o preenchimento do questionário composto com perguntas objetivas e uma questão aberta, esta que favorece o registro de alguma contribuição ou apontamento relevante. Mediante análise dos questionários respondidos, foi possível traçar o perfil característico dos servidores e evidenciar os principais fatores que motivaram a sua decisão de não migrar de regime de previdência.

\subsection{Gênero e Faixa etária do servidor}

No estudo realizado, do total de participantes, $100 \%$ dos servidores que responderam são do sexo masculino. Apesar de aproximadamente $20 \%$ dos servidores da Instituição Pública, objeto do estudo, serem do sexo feminino, nenhuma destas respondeu à pesquisa encaminhada por meio do link de acesso disponibilizado pela área de recursos humanos.

A idade do servidor é considerada uma questão de suma importância na decisão de migração para o RPC, pois servidores com idade próxima ao tempo necessário para cumprir os requisitos legais de aposentadoria não terão um tempo hábil para acumular uma reserva matemática que recompense a decisão de migrar de regime.

No presente estudo, aproximadamente 50\% dos servidores possuem tempo inferior a 15 anos para completar a idade mínima de aposentadoria (65 anos para homens e 60 anos para mulheres) e $90 \%$ com tempo inferior a 25 anos.

\subsection{Tempo de posse no cargo atual e cargo anteriormente ocupado}

A aposentadoria dos servidores públicos federais advém, dentre outros requisitos, com cinco anos no cargo efetivo, sendo, portanto, relevante averiguar o tempo de posse no cargo atual. No estudo verificou-se que $40 \%$ dos servidores ingressaram entre 01 de janeiro de 2004 e 04 de fevereiro de 2013; 30\% foram empossados entre 16 de dezembro de 1998 e 31 de dezembro de 2003; $20 \%$ entraram antes de 16 de dezembro de 1998 e apenas $10 \%$ foram nomeados no cargo a partir de 04 de fevereiro de 2013.

Como elucidado pela ANAFE (2018), os "servidores antigos", isto é, aqueles empossados no serviço público federal antes de 4 de fevereiro de 2013, estão submetidos a dois regimes diferenciados, decorrentes da Emenda Constitucional $n^{\circ} 41$, de 19 de dezembro de 2003 - "regime da integralidade" e "regime da média". Assim, nota-se que 50\% desses servidores tomaram posse em data anterior à 31 de dezembro de 2003, sendo submetidos ao regime da integralidade, com direito a incorporar o reajuste dos ativos em sua aposentadoria. Cabe ressaltar que os demais servidores também podem estar submetidos a tal regime, caso tenham ingressado no serviço público federal, municipal ou estadual em data anterior à citada e desde que não tenha decorrido tempo entre as datas de posse.

\footnotetext{
${ }^{4}$ https://forms.gle/JvPhjFjGGZw3AcYU7
} 
Já no regime da média, o servidor público que ingressou a partir de $1^{\circ}$ de janeiro de 2004 terá seu benefício calculado de acordo com a média das 80\% maiores remunerações (feitas para qualquer regime - RPPS ou RGPS - desde julho de 1994) atualizadas pelo IPCA para a data do cálculo e reajustado pelo mesmo índice e nas mesmas épocas do RGPS (ANAFE, 2018).

No tocante à ocupação de algum cargo de provimento efetivo antes de assumir a função atual na Instituição Pública objeto de estudo. Os dados obtidos mostram que na pesquisa realizada, apenas $30 \%$ dos servidores ocupavam cargo de provimento efetivo antes de ingressar no atual cargo. Esse percentual indica que, dos servidores que ingressaram após 31 de dezembro de 2003 (40\% dos servidores), alguns deles pode ter direito ao regime da integralidade, sendo os demais submetidos ao regime da média, conforme já exposto no presente estudo.

\subsection{Origem do cargo anterior ocupado e tempo de serviço público}

Em relação ao cargo anteriormente ocupado, questionou-se a origem deste, a fim de compreender a motivação da troca laboral. Os resultados apontam que 30\% dos servidores que ocuparam outro cargo de provimento efetivo antes de ingressar no atual, 66,7\% ocupavam cargo na esfera federal e 33,3\% na esfera estadual. Esses percentuais indicam que a maioria dos servidores migrou de cargo público dentro da própria esfera federal, o que pode ser justificado pela proposta salarial mais alta oferecida no cargo atual.

A aposentadoria dos servidores públicos federais é concedida a partir de 10 anos de efetivo exercício no serviço público, além de outros requisitos. Neste estudo, verifica-se que apenas um servidor não possui tempo de serviço público superior ao mínimo exigido pela legislação em vigor. Do total de servidores participantes do estudo, $40 \%$ ingressaram entre 16 de dezembro de 1998 e 31 de dezembro de 2003; 30\% iniciaram a função entre 01 de janeiro de 2004 e 04 de fevereiro de 2013; 20\% empossaram antes de 16 de dezembro de 1998 e apenas 10\% entraram no cargo a partir de 04 de fevereiro de 2013.

Dos servidores civis e ativos que ingressaram antes de 04 de fevereiro de 2013, a maioria ainda não realizou a migração, talvez por não disporem das informações necessárias, ou por desconhecerem qual seria a opção mais vantajosa para o recebimento da aposentadoria.

\subsection{Vacância entre posse nos cargos e pretensão de aposentadoria no serviço público federal}

Com relação à vacância entre o cargo ocupado no órgão anterior e a posse no atual cargo, que significa a descontinuidade (tempo ocioso) entre as funções desempenhadas, constatou-se que $80 \%$ dos servidores não possuíam vacância entre os dois cargos, pois as datas (de saída do cargo antigo e de entrada no cargo atual) ocorreram concomitantemente.

Esse resultado pode ter influenciado na decisão de migrar ou não de regime, pois caso a posse no novo cargo público federal não tenha ocorrido na mesma data da vacância no cargo anterior, o servidor pode ser enquadrado no regime da média, a depender da data de posse no novo cargo, interferindo, também, no valor da aposentadoria.

A existência de tempo anterior no RGPS/INSS ou em outro RPPS, que não o da União, gera efeitos contrapostos nas simulações. Por um lado, o tempo anterior não é computado para fins do Fator de Conversão, reduzindo o BE. Por outro, o tempo de RGPS/INSS é descartado no cálculo da média de remunerações base do BE, o que tende a elevar a média, diferentemente do que ocorre no regime antigo, no cálculo pelo regime da média, em que todas as contribuições, inclusive as feitas para o RGPS/INSS, são consideradas, desde que a partir de julho de 1994.

Quanto a intenção de se aposentar no serviço público federal, constatou-se que todos os participantes pretendem se aposentar no atual cargo. O servidor que, no regime antigo, estiver contribuindo sobre a totalidade da remuneração, e que deixar o serviço público, vincula-se novamente ao RGPS/INSS, averbando esse tempo de contribuição no RGPS/INSS, como se este tivesse sido feito pelo teto desse regime, tendo sido inúteis as contribuições incidentes sobre a parcela do salário que supera esse limite. 
No estudo verificou-se que $80 \%$ dos participantes pretendem se aposentar nos próximos 20 anos, sendo $50 \%$ entre 10 e 20 anos; $20 \%$ nos próximos cinco anos; e 10\% entre cinco e 10 anos. Além desses, $10 \%$ já entraram com o pedido/requerimento para a aposentadoria, ou seja, trata-se de uma fase iminente. Apenas 10\% responderam um tempo maior para conquista da aposentadoria (entre 20 e 30 anos), sendo estes os novos servidores.

\subsection{Remuneração do servidor e adesão ao Funpresp}

$\mathrm{Na}$ análise do perfil do servidor, para simulação dos cálculos dos valores referentes à futura aposentadoria, e para entendimento da não-migração para o regime da previdência complementar, verificou-se que $90 \%$ dos participantes possuem remuneração bruta maior que $\mathrm{R} \$ 20.000,00$, sendo, especificamente, $80 \%$ recebendo mais de $\mathrm{R} \$ 25.000,00$ e $10 \%$ entre $\mathrm{R} \$$ $20.000,00$ e $\mathrm{R} \$ 25.000,00$. Apenas $10 \%$ responderam que recebem a quantia de $\mathrm{R} \$ 15.000,00$ a $\mathrm{R} \$ 20.000,00$.

Ao realizar a simulação de migração para o regime de previdência complementar, considerando a soma das três parcelas do benefício (teto do RGPS, Benefício Especial e Funpresp), o valor obtido se torna mais difícil de superar o valor da remuneração do servidor submetido ao regime da integralidade, sobretudo pelo pouco tempo restante para a acumulação de sua reserva na Funpresp. Neste sentido, o valor do benefício especial, ao qual está atrelado ao tempo de serviço público, impacta diretamente na decisão da migração de regime.

Outro ponto relevante é que $80 \%$ dos participantes afirmaram que não irão realizar a migração de regime e $20 \%$ ainda não sabe se vai aderir. É válido ressaltar que a decisão de não migrar de regime de previdência é significativamente impactada pelo tempo de serviço público, pelo tempo restante para a aposentadoria e possibilidade de deixar o serviço público antes da aposentadoria.

No próximo item, elencam-se outros dados importantes relacionados à adesão e aos benefícios a serem acumulados a partir desta.

\subsection{Conhecimento dos benefícios}

Os servidores participantes foram questionados sobre o conhecimento das vantagens e desvantagens da adesão ao Plano de Benefícios da Funpresp-Exe. Neste quesito, tem-se que 70\% dos servidores afirmam conhecer todos os benefícios da Funpresp e 30\% conhecem parcialmente os benefícios do plano. Esse resultado também pode influenciar na tomada de decisão desses servidores, uma vez que a ampla divulgação sobre todos os benefícios ofertados pelo plano pode convencê-los a mudarem de opinião e realizarem a migração com a referida adesão.

Todos os servidores participantes têm conhecimento sobre a irrevogabilidade e irretratabilidade da decisão de migrar, ou seja, uma vez tomada a decisão, esta se torna irreversível.

\subsection{Fatores relacionados à decisão de migração}

Como exposto anteriormente, na Fundamentação Teórica, o servidor público que realizar a migração pode receber um benefício especial, adicionando o seu valor à sua aposentadoria, pago pelo RPPS da União, conforme contribuições efetuadas, tempo de contribuição, rentabilidade obtida pela entidade de previdência complementar, e custos administrativos incorridos (Rangel, 2013).

Amaral (2017) completa que o servidor também pode contribuir para a Funpresp, mesmo que perceba remuneração menor que o teto do RGPS. Assim, caso deseje complementar a sua aposentadoria, no caso daqueles que recebem acima do teto, conforme art. 16, § 3ํㅡ, da Lei no 12.618/2012: o Governo contribuirá com 7,5 a 8,5\%, na mesma proporção da contribuição. 
A partir de tais considerações, questionam-se aos participantes os fatores que influenciaram na decisão de não migrar, tendo as seguintes respostas como alternativas: a) Incerteza quanto ao valor futuro a receber de Benefício Especial; b) Incerteza quanto à segurança jurídica no pagamento futuro do Benefício Especial; c) Falta de conhecimento de todas as vantagens e desvantagens na migração; d) Incerteza quanto a mudanças que possam impactar nas regras que foram pactuadas para estimular a migração; e) Risco de má gestão dos investimentos no plano; f) Insegurança quanto a possível(is) alteração(ões) na regra de paridade das contribuições do patrocinador; g) Idade e/ou Tempo de contribuição restante para a aposentadoria; h) Outro. No Gráfico 1, apresentam-se as respostas obtidas em cada alternativa supracitada.

Gráfico 1: Caso não tenha migrado, quais fatores, na sua opinião, influenciaram essa decisão?

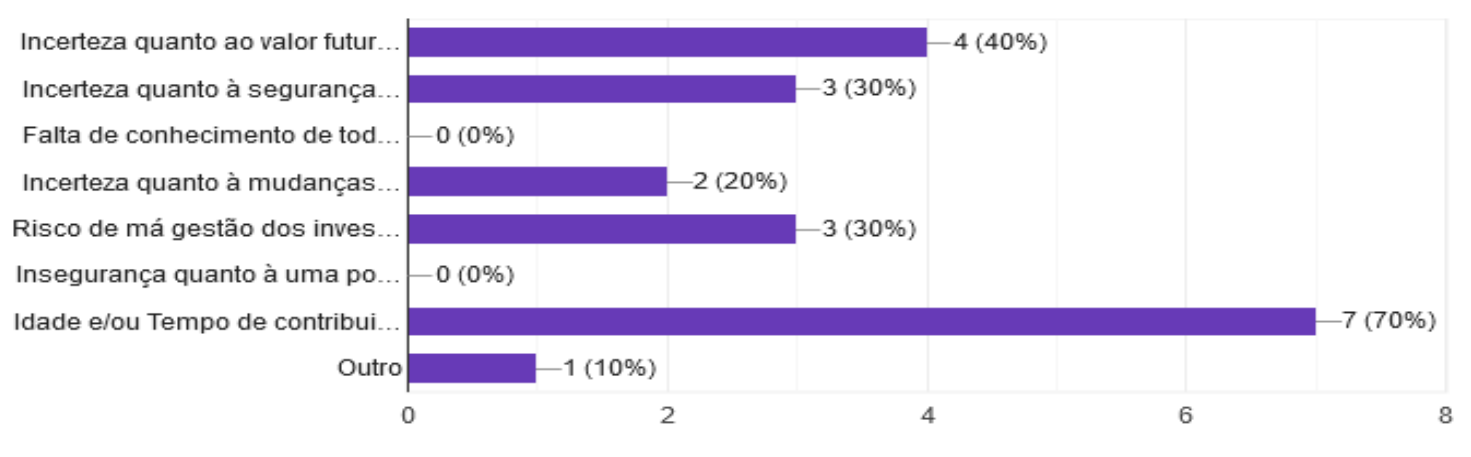

Fonte: Dados da pesquisa (2021).

Nota-se que a opção "idade e, ou, tempo de contribuição restante para a aposentadoria" consiste no principal fator para não realizar a migração (7 votos). Já a opção “incerteza quanto ao valor futuro do benefício especial” foi a segunda opção mais votada (4 votos), seguida pela "incerteza quanto à segurança jurídica no pagamento futuro do benefício especial" (3 votos) e "risco de má gestão nos investimentos do plano" (3 votos). Vale explicar que, nessa pergunta, os participantes puderam marcar mais de uma resposta.

Em estudo similar, Vasconcelos (2017) atesta que, para os servidores que irão migrar para a Previdência Complementar por períodos menores, a taxa de juros incidirá sobre este montante por este período menor (rentabilidade), fazendo com que a previsão de renda temporária não seja satisfatória para o complemento da renda na aposentadoria.

A partir dessas noções e para a continuidade nas especificações dos motivos que levaram à não migração, foi solicitado que os servidores justificassem sua decisão, permitindo, por fim, a compreensão da proposta deste estudo. Nas respostas dos participantes, percebe-se que $50 \%$ dos participantes responderam não haver nenhum outro fator, além dos já mencionados no Gráfico 1. Os demais participantes (50\%) alegaram fator financeiro, regra da paridade, incerteza das vantagens, valor e natureza do Benefício Especial, vantagem do benefício definido e longevidade.

Oliveira (2016), em sua pesquisa sobre os fatores determinantes para a decisão de servidores públicos na adesão à previdência complementar, conclui que a falta de confiança e de informação são as duas razões principais para a não adesão. $O$ autor sugere que o aumento da adesão pode advir de uma combinação de fatores que possam estimular os mecanismos institucionais de governança que conferem ao servidor certa segurança e favorecer a certificação da instituição e dos gestores.

É importante esclarecer que a melhor opção entre se manter no regime atual ou migrar para o novo regime não é universal, pois depende da situação individual de cada servidor, bem como de cenários econômicos e políticos - muitas vezes afetados por circunstâncias imponderáveis.

Em geral, para os novos servidores (ingressos a partir de 4 de fevereiro de 2013), a adesão à Funpresp-Exe configura a decisão mais racional. Trata-se de um investimento "acelerador" de rentabilidade, embora seja necessário considerar que nem 
todo valor contribuído é destinado à conta individual do servidor; além disso, contribuir com percentual superior ao limite de 8,5\% reduz a eficiência do investimento (ANAFE, 2018).

Para analisar as opções de investimento previdenciário no mercado atual, sabendo que o mercado de previdência complementar no Brasil está em constante crescimento, bem como o interesse dos servidores em sua adesão, recomenda-se investir em um plano de aposentadoria escolhendo o plano mais adequado a cada perfil, por meio de simulações que atestem o maior retorno financeiro.

\section{Considerações Finais}

O presente estudo teve como objetivo analisar o perfil dos servidores públicos federais de uma Instituição Pública e a motivação que os levaram a não migrarem para o Regime de Previdência Complementar Rio de Janeiro. Para tanto, analisou os principais fatores que motivam e influenciam a mudança para tal regime e se estão relacionados à idade e ao tempo de contribuição restante para a aposentadoria, à incerteza e à segurança jurídica quanto ao valor futuro do benefício especial e ao risco de má gestão dos investimentos.

Nesse sentido, importante destacar o Parecer n. 00601/2018/GCG/CGJOE/CONJUR-MP/CGU/AGU, de 29 de maio de 2018, que definiu, entre outros direitos, que o Benefício Especial possui natureza jurídica compensatória, não constituindo um benefício previdenciário em sentido estrito.

Assim, urge a necessidade de treinamentos nos órgãos de gestão de pessoas das Instituições Públicas visando orientar os servidores na decisão quanto à migração de regime previdenciário, além da implantação de sistemas que facilitem o mapeamento da situação de cada servidor quanto a aposentadoria e, por fim, a melhora na transparência e no processo decisório dos investimentos das EFPC, de forma a passar maior segurança para os participantes dos fundos de pensão. Importante ressaltar o fortalecimento do arcabouço regulatório, em especial, à Governança e aos Investimentos das EFPC, nos últimos anos.

Fica evidente que, apesar do conhecimento das vantagens do Plano de Benefícios oferecido pela Funpresp aos servidores públicos federais, estes, ainda, não se sentem seguros quanto à opção de migração, devido a diversas incertezas ou pela inviabilidade financeira quando comparada ao regime atual.

Diversos são os fatores que devem ser levados em consideração ao se decidir quanto à alternativa que mais se adequa ao perfil de cada servidor. A irretratabilidade da decisão faz com que a opção de migração de regime se torne ainda mais difícil, especialmente pelo fato de sua adequação depender de aspectos econômicos, políticos, jurídicos e pessoais futuros, muitos deles incertos e até imponderáveis.

Relativamente aos servidores que entraram no servido público federal a partir de 4 de fevereiro de 2013 e que, por isso, já terão suas aposentadorias limitadas ao teto do RGPS/INSS, a adesão à Funpresp-Exe, com contribuição igual ou superior a 8,5\% da remuneração base de contribuição (a parcela que excede o teto do RGPS/INSS), é a decisão racionalmente mais adequada, a menos que o servidor pretenda deixar o serviço público precocemente (em menos de 15 anos), resgatando, de uma só vez, os recursos que investiu na referida entidade.

A decisão por contribuir com $8,5 \%$ justifica-se no fato de que a União fará a contrapartida paritária à contribuição do servidor, até esse patamar. No entanto, dificilmente a contribuição de 8,5\% será suficiente para suprir uma aposentadoria em nível próximo ao último salário do servidor, a menos que o ingresso no serviço público tenha ocorrido com pouca idade (por volta dos 20 anos de idade). Assim, o servidor poderá realizar simulações para verificar, de acordo com o benefício esperado, quanto, além dos $8,5 \%$, deverá contribuir para que se chegue ao benefício pretendido. 
No que tange os servidores que entraram no serviço público antes de 4 de fevereiro de 2013, diversos são os aspectos que circundam a decisão pela migração, compreendendo a primeira decisão, que é a opção pelo Benefício Especial, e a segunda que se refere à adesão à Funpresp-Exe.

Nem sempre a decisão pela migração será a mais adequada. Porém, quando for, certamente estará vinculada à concomitante adesão à Funpresp-Exe, com contribuição mínima de 8,5\% sobre a parcela do salário que ultrapassar o teto do RGPS/INSS, valendo-se os mesmos comentários feitos em relação aos servidores que ingressaram a partir de 04 de fevereiro de 2013, em relação à conveniência de contribuições adicionais aos 8,5\% em outras entidades - abertas ou fechadas - de previdência complementar ou na própria Funpresp-Exe.

Além disso, constata-se que ações de melhoria se tornam necessárias quanto à forma de apresentar o plano, as propostas e limitações quanto à busca de melhores rendimentos que assegurem uma aposentadoria estável, para que aumente o número de adesões e para que o servidor se sinta mais seguro nessa migração.

Como limitações deste estudo, cita-se a falta de pesquisas realizadas sobre a temática, incluindo esclarecimentos sobre retornos dos investimentos dos recursos acumulados nas contas individuais, no que diz respeito à Previdência Complementar. Do mesmo modo, são escassos os trabalhos que abordam a ótica do governo federal. Especificamente, neste trabalho, o conteúdo esteve atrelado ao ponto de vista do servidor público. Por essa razão, recomenda-se a realização de novos estudos sobre os futuros impactos na conta pública sob a ótica do governo federal, podendo-se expandir para esferas municipais e estaduais.

\section{Agradecimentos}

O presente trabalho foi realizado com apoio da Coordenação de Aperfeiçoamento de Pessoal de Nível Superior (CAPES) - Código de Financiamento 001.

\section{Referências}

Amaral, E. A. (2017). Previdência no Brasil: o fundo de previdência complementar dos servidores públicos federais (FUNPRESP). Dissertação de Mestrado, Universidade Federal da Grande Dourados, Dourados, MS, Brasil. https://repositorio.ufgd.edu.br/jspui/handle/prefix/1177

Amaral, F. V. A., Giambiagi, F. \& Caetano, M. A. R. (2013). O fundo previdenciário dos servidores da União: resultados atuariais. Pesquisa e Planejamento Econômico, v. 43, n. 1, p. 119-160.

Angoti, L. R. M. (2012). A Previdência complementar e sua regulação no Brasil. Revista Jus Navigandi, ano 17, v. 32, n. 56. https://jus.com.br/artigos/21892.

Associação Nacional dos Advogados Públicos Federais (2018). Estudo sobre a opção de migração de regime previdenciário aplicável aos servidores públicos federais empossados antes de 4 de fevereiro de 2013. https://snacional.org.br/wp-content/uploads/2018/02/ANAFE-ESTUDO-PREV-SERVP\%C3\%9ABLICO-Funpresp.pdf.

Batista, V. (2020). Servidores querem novo prazo para migração à Funpresp. https://blogs.correiobraziliense.com.br/servidor/tag/rpc/.

Biancolino, C. A.; Kniess, C. T.; Maccari, E. \& Rabechini Jr, R. (2011). Protocolo para elaboração de relatos de produção técnica. Revista de Gestão e Projetos -GeP, 3(2), 294-307.

Cazassa, V. (2002). Os fundos de pensão na atualidade. Dissertação de Mestrado, Universidade Federal do Rio Grande do Sul, Porto Alegre, RS, Brasil. https://lume.ufrgs.br/handle/10183/10122

Cervo, A. L. \& Bervian, P. A. (2002). Metodologia Científica. 5 ed. São Paulo: Prentice Hall.

Chaba, V. (2013). O novo paradigma da previdência complementar dos Servidores Públicos Federais e as mudanças trazidas com a criação da FUNPRESP. Dissertação de Mestrado, Pontifícia Universidade Católica do Rio de Janeiro, Rio de Janeiro, RJ, Brasil. http://www.financasaplicadas.net/index.php/financasaplicadas/article/view/261

Constituição da República Federativa do Brasil de 1988. (2001). [Coleção Saraiva de Legislação]. (21a ed.). São Paulo: Saraiva.

Creswell, J. W. (2014). Investigação qualitativa e projeto de pesquisa (3a ed.). Porto Alegre: Penso.

Emenda Constitucional $\mathrm{n}^{\circ}$ 20, de 15 de dezembro de 1998 (1998). Modifica o sistema de previdência social, estabelece normas de transição e dá outras providências. https://www.camara.leg.br/proposicoesWeb/prop_mostrarintegra?codteor=725531\&filename=LegislacaoCitada+-PL+6613/2009. 
Emenda Constitucional n ${ }^{\circ}$ 41, de 19 de dezembro de 2003 (2003). Modifica os arts. 37, 40, 42, 48, 96, 149 e 201 da Constituição Federal, revoga o inciso IX do $\$ 3$ do art. 142 da Constituição Federal e dispositivos da Emenda Constitucional $n^{\circ}$ 20, de 15 de dezembro de 1998, e dá outras providências. Diário Oficial da União. Brasília, DF.

Filho, E. N. C. (2015). A importância da previdência complementar para previdência social e para o poder de compra dos futuros aposentados no Brasil. Dissertação de Mestrado, Universidade Federal Fluminense, Niterói, RJ, Brasil. https://app.uff.br/riuff/handle/1/1479

Fundação de Previdência Complementar do Servidor Público Federal do Poder Executivo (2020). Análise e manifestação pela Consultoria-Geral da União sobre o Parecer Jurídico $n^{o}$ 30/2018/GEJUR/Funpresp-Exe, de 30 de abril de 2018, elaborado pela Gerência Jurídica da Funpresp. Brasília, DF. https://www.funpresp.com.br/wp-content/uploads/2020/07/Parecer-AGU.pdf.

Fundação de Previdência Complementar do Servidor Público Federal do Poder Executivo. (2020). Regulamento do Plano de Benefícios da Previdência Complementar do Poder Executivo Federal. Brasília, DF, 2020. https://www.funpresp.com.br/wp-content/uploads/2020/11/Regulamento-ExecPrev19.03.2021.pdf.

Giambiagi, F. (2007). Reforma da previdência: o encontro marcado. Rio de Janeiro: Editora Elsevier.

Gil, A. C. (2008). Como elaborar projetos de pesquisa. 5. ed. São Paulo: Atlas.

Kertzman, I. \& Martinez, L. (2018). Guia prático da Previdência Social. 6 ed. São Paulo: Editora JusPodvm.

Lei complementar $\mathrm{n}^{\circ}$ 108, de 29 de maio de 2001 (2001). Dispõe sobre a relação entre a União, os Estados, o Distrito Federal e os Municípios, suas autarquias, fundações, sociedades de economia mista e outras entidades públicas e suas respectivas entidades fechadas de previdência complementar, e dá outras providências. Diário Oficial da União. Brasília, DF.

Lei complementar $\mathrm{n}^{\circ}$ 109, de 29 de maio de 2001 (2001). Dispõe sobre o Regime de Previdência Complementar e dá outras providências. Diário Oficial da União. Brasília, DF.

Lei n ${ }^{\circ}$ 6.435, de 15 de julho de 1977 (1977). Dispõe sobre as Entidades de Previdência Privada. http://www.planalto.gov.br/ccivil_03/LEIS/L6435.htm.

Lei $\mathrm{n}^{\circ}$ 12.618, de 30 de abril de 2012 (2012). Institui o regime de previdência complementar para os servidores públicos federais titulares de cargo efetivo, inclusive os membros dos órgãos que menciona; fixa o limite máximo para a concessão de aposentadorias e pensões pelo regime de previdência de que trata o art. 40 da Constituição Federal. Diário Oficial da União. Brasília, DF.

Lei $\mathrm{n}^{\circ}$ 13.328/2016, de 29 de julho de 2016 (2016). Cria, transforma e extingue cargos e funções; reestrutura cargos e carreiras; altera a remuneração de servidores; altera a remuneração de militares de ex-Territórios Federais; altera disposições sobre gratificações de desempenho; dispõe sobre a incidência de contribuição previdenciária facultativa sobre parcelas remuneratórias; e modifica regras sobre requisição e cessão de servidores. Diário Oficial da União. Brasília, DF.

Lei complementar $\mathrm{n}^{\circ} 13.809$, de 21 de fevereiro de 2019 (2019). Reabre o prazo para opção pelo regime de previdência complementar de que trata o $\$ 7^{\circ}$ do art. $3^{\circ}$ da Lei $n^{\circ} 12.618$, de 30 de abril de 2012. Diário Oficial da União. Brasília, DF.

Ludke, M. \& Andre, M. E . D. A. (2013). Pesquisas em educação: uma abordagem qualitativa. São Paulo: E.P.U.

Martens, C. D. P. \& Pedron, C. D. (2019). A disseminação da produção técnica/tecnológica gerada em programas stricto sensu profissionais. Revista Inovação, Projetos e Tecnologias. São Paulo, v. 7, n. 1, Editorial, Jan/Jun,

Oliveira, J. L. M. T. (2016). Fatores determinantes para a decisão de servidores públicos na adesão à previdência complementar. Dissertação de Mestrado, Escola Brasileira de Administração Pública e de Empresas da Fundação Getúlio Vargas - EBAPE/FGV, Rio de Janeiro, RJ, Brasil. http://bdtd.ibict.br/vufind/Record/FGV_ff6f6eb66d44cbbdc79a5fce039b2cdc

Organização para Cooperação e Desenvolvimento Econômico (2009). Previdência Complementar: OCDE destaca importância da previdência privada no mundo. https://mps.jusbrasil.com.br/noticias/1547428/previdencia-complementar-ocde-destaca-importancia-da-previdencia-privada-no-mundo.

Paixão, L. A. (2007). A Previdência Complementar fechada: uma visão geral. http://www1.previdencia.gov.br/docs/pdf/SPC-uma-visao-geral.pdf.

Parecer $\mathrm{n}^{\circ}$ 00601/2018/GCG/CGJOE/CONJUR-MP/CGU/AGU, de 29 de maio de 2018. Sistema remuneratório e benefícios. https://www.funpresp.com.br/wp-content/uploads/2020/07/Parecer-AGU.pdf.

Pereira A. S. et al. (2018). Metodologia da pesquisa científica. [free e-book]. Santa Maria/RS. Ed. UAB/NTE/UFSM.

Pena, R. (2014). Funpresp: construir as bases para uma previdência forte. Secretaria de Políticas de Previdência Complementar - SPPC, Previdência Complementar, Ano 2, n. 2.

Pinheiro, R. P. A (2008). Demografia dos fundos de pensão. Ministério da Previdência Social. Secretaria de Políticas de Previdência Social. Coleção Previdência Social. Série estudos, v. 24. Brasília, DF.

Portaria MPS/PREVIC/DITEC n ${ }^{\circ}$ 44, de 31 de janeiro de 2013 (2013). Aprova o regulamento do Plano Executivo Federal, administrado pela Fundação de Previdência Complementar do Servidor Público Federal do Poder Executivo - Funpresp - Exe. Diário Oficial da União. Brasília, DF.

Portaria $\mathrm{n}^{\circ}$ 604, de 19 de outubro de 2012 (2012). Aprova a constituição e autoriza o funcionamento da Fundação de Previdência Complementar do Servidor Público Federal do Poder Executivo - Funpresp - Exe. Diário Oficial da União. Brasília, DF.

Pulino, D. (2011). Previdência Complementar - Natureza jurídico-constitucional e seu desenvolvimento pelas Entidades Fechadas. São Paulo: Conceito.

Rangel, L. A. (2013). A criação da previdência complementar dos servidores públicos e a instituição de um teto para os valores dos benefícios: Implicações na Distribuição de Renda e na Taxa de Reposição das Aposentadorias. Tese de Doutorado, Universidade Federal do Rio de Janeiro, Rio de Janeiro, RJ, Brasil. 
Research, Society and Development, v. 10, n. 11, e549101120031, 2021

(CC BY 4.0) | ISSN 2525-3409 | DOI: http://dx.doi.org/10.33448/rsd-v10i11.20031

Ricaldoni, C. M. (2012). Previdência Complementar - Perspectivas e Aspectos Legais Fundamentais. Seminário Internacional de Previdência Complementar dos Servidores Públicos Federais - ANFIP, Belo Horizonte, MG, Brasil.

Selltiz, C.; Wrightsman, L. S. \& Cook, S. W. (1965). Métodos de pesquisa das relações sociais. São Paulo: Herder.

Superintendência Nacional de Previdência Complementar (2021). Relatório de Estabilidade da Previdência Complementar- junho 2021, Brasília, DF. https://www.gov.br/economia/pt-br/orgaos/entidades-vinculadas/autarquias/previc/centrais-de-conteudo/publicacoes/relatorio-de-estabilidade-da-previdenciacomplementar-rep/6deg-edicao-do-relatorio-de-estabilidade-da-previdencia-complementar-rep-junho-de-2021.pdf.

Superintendência Nacional de Previdência Complementar (2020). Relatório Integrado Previc 2020. Brasília, DF, 2020. https://www.gov.br/economia/ptbr/orgaos/entidades-vinculadas/autarquias/previc/acesso-a-informacao/transparencia/relato-integrado/relato-integrado-previc-2020.pdf/view.

Vasconcelos, R. C. P. (2017). Funpresp-exe: vantagens e desvantagens na adesão do servidor público. Dissertação de Mestrado, Universidade Federal de Alfenas, Varginha, MG, Brasil. https://bdtd.unifal-mg.edu.br:8443/handle/tede/974

Vergara, S. C. (2003). Projetos e relatórios de pesquisa em administração (4a ed.), São Paulo: ATLAS.

Yin, R. K. (2016). Pesquisa qualitativa do início ao fim. Porto Alegre: Penso. 